\title{
DIVERGÊNCIA GENÉTICA ENTRE ACESSOS DE Passiflora cincinnata Mast COM BASE EM DESCRITORES MORFOAGRONÔMICOS ${ }^{1}$
}

\author{
FRANCISCO PINHEIRO DE ARAÚJO², NORBERTO DA SILVA , MANOEL ABÍLIO DE QUEIROZ4
}

RESUMO - Este trabalho teve como finalidade estimar a divergência genética entre acessos de maracujazeiro (Passiflora cincinnata Mast.) conservados na coleção de trabalho da Embrapa Semi-Árido, em Petrolina-PE. O experimento foi conduzido em delineamento de blocos ao acaso, com quatro repetições. A avaliação foi realizada em 32 acessos, com base em 23 caracteres: dois relativos à planta, três às folhas, seis às flores, quatro aos frutos, quatro às sementes, dois às características químicas dos frutos e dois à produção. $\mathrm{O}$ comportamento dos acessos foi pesquisado pelas análises univariada e multivariada, com estimativas das dissimilaridades obtidas pela distância generalizada de Mahalanobis $\left(\mathrm{D}^{2}\right)$ e formação do agrupamento pelo método de Tocher. Os acessos apresentaram variabilidade genética para todos os descritores utilizados na avaliação. As distâncias genéticas entre pares de acessos variaram de 17 a 598, com média 152. O acesso 18-D0542 foi indicado como o mais divergente e o mais produtivo, devendo compor programas de intercruzamentos e ser recomendado para cultivos experimentais por produtores. As características de maior importância para a divergência genética foram: a massa total dos frutos (42,29\%), a viabilidade de pólen (8,62\%) e a área foliar (7,16\%). O agrupamento dos acessos não se correlaciona às Unidades Geoambientais originais de coleta.

Termos para indexação: variabilidade, morfologia, análise multivariada, maracujá, germoplasma.

\section{GENETIC DIVERGENCE AMONG PASSIFLORA CINCINNATA MAST ACCESSIONS BASED ON MORPHOAGRONOMIC DESCRIPTORS}

\begin{abstract}
This study had the objective of evaluating the genetic divergence among passion fruit (Passiflora cincinnata Mast.) accessions maintained in the collection of Embrapa Tropical Semi-Arid, Petrolina-PE, Brazil. The experiment was carried out in a randomized complete block design with four replications. Thirty-two accessions were evaluated considering thirty-three characters: two related to the plant, three to the leaves, six to the flowers, four to the fruits, four to the seeds, two to the chemical characteristics of fruits and two to the yield. The behaviour of accessions was evaluated by univariate and multivariate analyses, with dissimilarities obtained by the generalized distance of Mahalanobis $\left(\mathrm{D}^{2}\right)$ and the grouping technique by the Tocher method. The accessions showed genetic variability for all the evaluated descriptors. The genetic distances between pairs of accessions ranged from 17 to 598, with an average of 152. The accessions indicated as the most divergent should be included in intercross programs and recommended to experimental growing at farm level. The characteristics which most contributed to genetic divergence were total fruit yield (42.29\%), pollen viability $(8.62 \%)$ and leaf area $(7.16 \%)$. The accessions grouping was not correlated to the original Geo-Environmental Units. Index terms: variability, morphology, multivariate analysis, passion fruit, germplasm.
\end{abstract}

\section{INTRODUÇÃO}

A família Passifloraceae compreende cerca de 19 gêneros e 530 espécies, com distribuição tropical e subtropical, particularmente da América e África. Desses gêneros, cinco ocorrem no Neotrópico, abrangendo quase 400 espécies e quatro gêneros no Brasil, com cerca de 130 espécies (Bernacci, 2003). Por tradição, os cultivos comerciais em quase todo o País basicamente são realizados com o maracujá-amarelo ou azedo (Meletti et al., 2005). O Brasil destaca-se como o maior produtor mundial desse maracujá (Ferreira, 2005), e a região Nordeste do Brasil é a principal produtora, responsável por $44 \%$ da produção, com uma área cultivada de 17.306 ha e cerca de 214.467 t anuais, destacando-se os Estados da Bahia, Ceará e Sergipe como os maiores produtores (AGRIANUAL, 2006).

Conforme Meletti et al. (2005) e Junqueira et al. (2005), algumas espécies de Passiflora silvestres têm grande potencial para contribuir com o melhoramento genético do maracujazeiro comercial, por apresentarem, além da resistência a doenças e a algumas pragas, outras características interessantes, como longevidade, autocompatibilidade, maior adaptação a condições climáticas adversas, período de florescimento ampliado, androginóforo mais curto, que facilita a polinização por insetos menores, e maior concentração de componentes químicos. O cultivo em escala doméstica, com comercialização restrita à região

'(Trabalho 235-07) Recebido em: 03-10-2007. Aceito para publicação em: 15-05-2008. Parte da tese de doutorado do primeiro autor, em agronomia, área de concentração em Horticultura, na UNESP/FCA, Botucatu-SP

${ }^{2} \mathrm{Eng}^{\circ} \mathrm{Agr}^{\circ}$ Dr., Embrapa Semi-Árido, Caixa Postal 23, CEP 56302-970 Petrolina-PE. E-mail pinheiro@cpatsa.embrapa.br

${ }^{3}$ Eng $^{\text {o }}$ Agr ${ }^{\circ}$ Prof. Dr., Universidade Estadual Paulista Júlio de Mesquita Filho, Departamento de Produção vegetal UNESP Fazenda experimental de Lageado. Caixa Postal 237 CEP 18610-307 Botucatu-SP. E-mail norbertosv@fca.unesp.br

${ }^{4}$ Eng $^{\circ}$ Agr $^{\circ}$ Prof. Dr., Universidade do Estado da Bahia, Av. Edgard Chastinet Guimarães s/n Caixa Posta 171 CEP $48905-680$ Juazeiro -BA. E-mail manoelabilio@terra.com.br 
de cultivo das espécies de maracujá-suspiro ( $P$. nitida), maracujámelão ( $P$. quadrangularis), e maracujá-tubarão ( $P$. cincinnata), foi relatado por Inglez de Souza \& Meletti (1997).

Embora as pesquisas com maracujazeiros estejam amplamente dirigidas às espécies cultivadas e, principalmente, a P. edulis, existem várias espécies silvestres de maracujazeiros com potencial agronômico que não têm recebido atenção da pesquisa, como, por exemplo, $P$. cincinnata, de ocorrência espontânea na região semi-árida do Nordeste brasileiro.

Vale salientar, também, que, no Semi-Árido do Nordeste brasileiro, as espécies silvestres estão ameaçadas. A fragmentação de habitats tem ocasionado, de forma direta ou indireta, perda da diversidade genética na região. As causas dessas perdas, atuando em conjunto ou isoladamente, relatadas por Queiroz et al. (1992), são a formação de pastagens, a implantação de projetos de irrigação, a produção de energia para atividades diversas e as queimadas. Assim sendo, é necessário que essas espécies sejam resgatadas, descritas e avaliadas para poderem ser usadas em futuros programas de melhoramento.

Os estudos taxonômicos em Passiflora baseiam-se na caracterização morfológica e agronômica da planta, levando a uma classificação segura até o táxon espécie. No entanto, o gênero Passiflora apresenta mais de 400 espécies que englobam, 23 subgêneros, muitas seções e séries e tem sido objeto também de estudos moleculares (Muschner et al., 2003). Outros estudos levaram a uma nova organização taxonômica do gênero Passiflora, propondo-se a utilização de apenas quatro subgêneros : Astrophea, Deidamioides, Decaloba e Passiflora (Feuillet \& MacDougal, 2004).

Porém, dentro das espécies, as dissimilaridades existentes apresentam maiores dificuldades para serem observadas e caracterizadas (Crochemore et al., 2003). Para Dias et al. (1997), a divergência entre acessos, avaliada por estatística multivariada, pode proporcionar uma descrição sintética da afinidade fenética e genética entre acessos e populações. Assim, a quantificação da dissimilaridade genética é um dos mais importantes parâmetros estimados pelos melhoristas de plantas, principalmente quando o objetivo for a obtenção de segregantes transgressivos e populações de ampla variabilidade genética (Benin et al., 2003).

A análise univariada pode identificar a existência de variabilidade entre indivíduos e os diferentes graus de discriminação dos mesmos, considerando cada descritor isoladamente. No entanto, para se fazer uma análise do poder discriminatório dos descritores, torna-se necessário analisar a contribuição dos mesmos de forma conjunta. Isso é possível com o uso de análises multivariadas. Sendo assim, as análises por componentes principais e variáveis canônicas e os métodos aglomerativos podem ser aplicados, pois os mesmos avaliam os indivíduos em vários aspectos (Cruz et al., 2004).

$\mathrm{Na}$ quantificação da divergência genética entre indivíduos, tem sido utilizada a técnica de aglomeração, que é baseada na distância Euclidiana média ou na distância generalizada de Mahalanobis $\left(\mathrm{D}^{2}\right)$, e a técnica de agrupamento tem sido feita pelo método de Tocher (Cruz \& Carneiro, 2003).

$\mathrm{O}$ presente trabalho foi desenvolvido com a finalidade de estimar a divergência genética entre acessos de $P$. cincinnata, distribuídos em diferentes regiões agroecológicas do Nordeste brasileiro por meio de descritores morfoagronômicos.

\section{MATERIAL E MÉTODOS}

O experimento foi instalado em abril de 2005, no Campo Experimental de Manejo da Caatinga, da Embrapa Semi-Árido, Petrolina-PE, em solo classificado como Argissolo. O municipio está situado a $09^{\circ} 09^{\prime}$ de latitude sul e a $40^{\circ} 22^{\prime}$ de longitude oeste, a uma altitude de $365 \mathrm{~m}$. O clima, segundo a classificação de Köeppen, é considerado como semi-árido quente BSwh', com uma precipitação pluvial média anual de $570 \mathrm{~mm}$.

A coleção foi obtida por meio de coletas com base na informação do Zoneamento Agroecológico do Nordeste (Silva et al., 2000), em 18 Unidades Geoambientais - UGs: sete acessos foram coletados na Unidade Geoambiental $\mathrm{C} 07$, seis na F22, cinco na A04 e na F23, quatro na B04, F26 e J08, três na F13, dois na A05, B05, D05, E05 e T03 e um na F11, F16, F29, F30 e I1 1, em 34 municípios dos Estados da Bahia, Ceará, Paraíba, Pernambuco e Piauí. Os tratamentos compreenderam 32 acessos de $P$. cincinnata (Tabela 1). Os acessos coletados em populações de ocorrência espontânea foram arranjados em delineamento experimental de blocos ao acaso, com quatro repetições, e duas plantas na parcela, espaçadas de 2,0 $\mathrm{m}$ x 5,0 m, no sistema de espaldeira, com um fio de arame situado a $1,80 \mathrm{~m}$ do nível do solo, utilizando-se de bordadura lateral em toda a área experimental.

Foram utilizados os seguintes descritores para avaliar os acessos:

1. Descritores das plantas (2) - diâmetro das hastes (DH), tomado na parte basal do caule e expressa em $\mathrm{cm}$ e comprimento médio do internódio em $\mathrm{cm}(\mathrm{CIH})$, medido até a altura de $1,0 \mathrm{~m}$ do colo das plantas.

2. Descritores das folhas (3): área foliar (AF), medida com aparelho LI-COR 3100 digital de leitura direta $\mathrm{em}^{2} \mathrm{~cm}^{2}$, comprimento do pecíolo (CMP) de cinco folhas e número de glândulas foliares (NGF) contadas na parte abaxial das cinco primeiras folhas. Todos esses caracteres foram aferidos quando a planta atingiu o arame de sustentação, a $1,80 \mathrm{~m}$ do nível do solo.

3. Descritores das flores (6): número de dias para abertura da primeira flor (DAF), contados do transplantio das mudas para o local definitivo até a abertura da primeira flor, diâmetro das flores em cm (DFL) e viabilidade de pólen em \% (VP), coletado em cinco botões florais na pré-antese. As anteras foram retiradas, esmagadas entre lâmina e lamínula de vidro e coradas com Carmim acético a $1,2 \%$ (Radford et al., 1974). A viabilidade foi obtida com a contagem média de 300 grãos de pólen, sendo considerados viáveis os corados. O comprimento dos filamentos externos da flor (CFE) foi aferido em cinco flores, tomando-se o comprimento em $\mathrm{cm}$ da base à extremidade dos filamentos. O comprimento em cm das brácteas $(\mathrm{CB})$ e o número de glândulas nas brácteas (NGB) foram obtidos de cinco brácteas na pré-antese das flores.

4. Descritores dos frutos (4): massa média dos frutos em gramas (MF), comprimento (CF), diâmetro (DF) e espessura da casca (ECF), em cm, obtidos de cinco frutos maduros por planta, quando os mesmos apresentavam sinais de amaciamento 
colhidos no período de outubro a dezembro.

5. Descritores das sementes (4): número de sementes por fruto (NSF), obtidos de cinco frutos, massa em gramas de 100 sementes (MS), comprimento das sementes (CS) e largura das sementes (LS), em mm, tomando-se cinco sementes de cada fruto.

6. Descritores dos caracteres químicos dos frutos (2): sólidos solúveis(SS), expressos em ${ }^{\circ B}$ Brix, determinado por refratômetro digital da marca "ABBE MARK-II", tomando-se cinco frutos por planta. A metodologia empregada foi de acordo com AOAC (1992). A acidez titulável (AT) foi expressa em gramas de ácido cítrico por $100 \mathrm{ml}$ de suco, de acordo com as Normas Analíticas de Métodos Químicos e Físicos para Análises de Alimentos, do Instituto Adolfo Lutz (IAL, 1985).

7. Descritores da produção (2): número total de frutos por planta (NFT) e massa total de frutos (MTF), kg/planta.

Dos 23 caracteres analisados, os descritores NGF, NGB, DAF, VP, NSF e NFT foram transformados em $\sqrt{\mathrm{x}+0,5}$. Os caracteres foram avaliados por métodos univariados e multivariados. Na análise multivariada, empregou-se a técnica de análise de agrupamento, realizada em 23 caracteres preliminares, por meio do método de otimização de Tocher, tendose, como medida de dissimilaridade, as distâncias generalizadas de Mahalanobis $\left(\mathrm{D}^{2}\right)$ (Rao, 1952). As análises foram realizadas com o emprego do programa computacional GENES (Cruz, 2001).

\section{RESULTADOS E DISCUSSÃO}

Os quadrados médios obtidos das análises de variância para os 23 caracteres analisados são apresentados na Tabela 2. Diferenças significativas $(\mathrm{p}<0,01)$ foram observadas entre as médias dos acessos de $P$. cincinnata para todos os caracteres avaliados, o que evidencia variabilidade genética suficiente para efetuar a seleção dos melhores acessos. O coeficiente de variação oscilou entre 4,16 e 12,95\%, demonstrando existir boa precisão experimental na análise de todos os caracteres considerados, mesmo aquelas relacionados à produção, que são complexos e mais sucetíveis à variação ambiental (Allard, 1971).

A análise univariada mostrou a existência de variabilidade genética entre os acessos, comprovando, também, que os descritores utilizados apresentaram diferentes graus de discriminação dos mesmos. O presente trabalho mostrou que, mesmo dentro de uma única espécie de maracujazeiro, encontrase expressiva variabilidade para vários caracteres de interesse agronômico. Por exemplo, a viabilidade de pólen variou entre os acessos, assim como a produção de frutos, ambos caracteres que devem ser considerados em programas de melhoramento de maracujazeiro. Em outros trabalhos da literatura nos quais se encontram diferenças expressivas para vários caracteres, os autores estudaram diferentes espécies, porém em um número limitado de acessos de cada respectiva espécie. Por exemplo, Meletti et al. (1992) avaliaram vários acessos de, pelo menos, oito espécies, sendo apenas um acesso de $P$. cincinnata. Outro caráter que também apresentou grande variabilidade, foi a área foliar, um atributo de interesse potencial quando se cultiva o maracujazeiro para exploração de produtos farmacêuticos, pois as substâncias usadas na medicina são encontradas principalmente nas folhas (Costa \& Tupinambá, 2005).

As distâncias generalizadas de Mahalanobis, que medem o grau de dissimilaridade $\left(\mathrm{D}^{2}\right)$ entre pares de acessos, encontramse na Tabela 3. A maior distância foi verificada entre os acessos 12-C0703 e 18-D0542 ( $\left.{ }^{2}=598\right)$, e a menor, entre os acessos 25 F2331 e 26-F2333 $\left(\mathrm{D}^{2}=17\right)$, o que significa que os acessos 12 C0703 e 18-D0542 são geneticamente os mais divergentes, e 25F2331 e 26-F2333, os mais similares.

A distribuição das distâncias genéticas, feita com base nos 496 pares gerados entre os acessos, está representada na Figura 1. Observa-se que a distribuição de distâncias genéticas nas quatro primeiras classes representou $76 \%$ das combinações entre pares de acessos coletados na mesma Unidade Geoambiental, ou seja, acessos geneticamente próximos, enquanto os pares de acessos procedentes de Unidades Geoambientais distintas representaram apenas $17 \%$. Essa maior concentração, revelando proximidade genética entre acessos, pode estar diretamente ligada às características dos próprios acessos durante a história evolutiva, uma vez que há maior probabilidade de encontrar descendentes próximos, dispersos em pequenas distâncias.

Analogamente, as divergências genéticas entre os acessos provenientes de Unidades Geoambientais distintas foram evidenciadas pela alta distribuição das distâncias estimadas. A maioria dos pares (83\%) está compreendida após a quinta classe, principalmente entre a quinta e a décima oitava classe, revelando, portanto, distâncias maiores decorrentes de fortes divergências genéticas (Figura 1). Dessa forma, observase que acessos relativamente próximos são provenientes de uma mesma Unidade Geoambiental, embora possam encontrar-se acessos próximos em diferentes Unidades Geoambientais. Isso pode ser resultante da dispersão de indivíduos geneticamente semelhantes por influência antrópica, no passado e até em tempos recentes, devido ao extrativismo observado com a espécie $P$. cincinnata. Por outro lado, nota-se que também dentro da mesma Unidade Geoambiental se observam algumas distâncias mais elevadas associadas a um determinado acesso, como, por exemplo, o acesso 18-D0542 (Tabela 3).

A utilização do método de otimização de Tocher, fundamentado na dissimilaridade expressa pelas distâncias de Mahalanobis $\left(\mathrm{D}^{2}\right)$, permitiu a formação de seis grupos distintos (Tabela 4). De modo geral, houve baixa correlação entre a procedência dos acessos referente à Unidade Geoambiental e a inserção dos mesmos nos grupos, pois apenas $25 \%$ dos acessos foram agrupados de acordo com a origem ecogeográfica. Essa situação pode ser resultante de características específicas de certos acessos. Por exemplo, no presente estudo, as dez maiores distâncias de $\mathrm{D}^{2}$ (462 a 598) estavam relacionadas ao acesso 18D0542, indicando-o, assim, como o mais divergente. Portanto, a variação encontrada nos acessos não está necessariamente associada às variações do ambiente. Fato semelhante foi constatado por Oliveira et al. (2003), para feijão-caupi, e Peter \& Raí (1976), citados por Cruz (1990), para tomate. Esses resultados mais uma vez reforçam a influência antrópica antiga e recente na dispersão da variabilidade de P. cincinnata no Semi-Árido do Nordeste brasileiro. É possível que os acessos que foram 
agrupados de acordo com a origem agroecológica, ou seja, os acessos originários da UGs $\mathrm{C} 07$ e B05, encontrem-se em regiões mais isoladas, comparados com os demais.

Na Tabela 5, estão relacionados todos os descritores analisados no estudo da caracterização morfoagronômica. A identificação dos descritores mais importantes foi realizada de acordo com o critério proposto por Singh (1981), considerandose as características de maior contribuição relativa para a divergência. Os caracteres que mais contribuíram para a diversidade genética, foram: massa total de frutos $(42,29 \%)$, viabilidade de pólen $(8,62 \%)$, área foliar $(7,17 \%)$, número de glândulas nas brácteas $(5,88 \%)$, diâmetro das hastes $(4,99 \%)$, massa dos frutos $(4,03 \%)$, massa de 100 sementes $(3,56 \%)$, número de glândulas foliares $(2,82 \%)$ e comprimento das brácteas $(2,64 \%)$, que, juntos, representaram $82 \%$ da variabilidade existente entre os acessos avaliados.

$\mathrm{Na}$ Tabela 6, são apresentadas as correlações parciais entre as combinações dos descritores de maior importância e de menor importância na caracterização de $P$. cincinnata. Os descritores selecionados apresentaram coeficientes de correlação de baixa magnitude, exceto para a correlação entre os descritores AF com CMP, MS com LS e MTF com NFT. Conforme metodologia de Singh (1981), em razão de esses descritores explicarem a mesma variação que descritores de maior importância, são considerados redundantes e passíveis de eliminação em trabalhos de caracterização morfológica de $P$. cincinnata.
Crochemore et al. (2003) identificaram os descritores comprimento do espiral da gavinha (CEG), comprimento dos internódios das hastes $(\mathrm{CIH})$, cor da casca do fruto (CCF) e cor da polpa do fruto (COP) como discriminantes, enquanto os descritores área foliar (AF), diâmetro das hastes (DH) e número de glândulas foliares (NGF) não apresentaram valor discriminante, embora tenham sido bastante discriminantes no presente trabalho. Embora as análises de ambos os trabalhos se baseiem em experiências de apenas um ano, é possível que a falta de concordância se deva a diferentes espécies consideradas nos dois trabalhos. Ainda mais, no presente trabalho, com acessos de $P$. cincinnata, o caráter massa total de frutos explicou a maior parte da variação entre os acessos avaliados, encontrando-se acessos muito produtivos. Esse resultado também reforça o argumento anteriormente apresentado de influência antrópica na seleção de tipos produtivos de $P$. cincinnata.

Considerando que os descritores que mais se destacaram, são caracteres quantitativos e, portanto, influenciados pelo ambiente (Allard, 1971), para se ter mais segurança na escolha de descritores destinados a avaliar acessos de $P$. cincinnata, é desejável a inclusão de novos ambientes e de mais anos de observação.

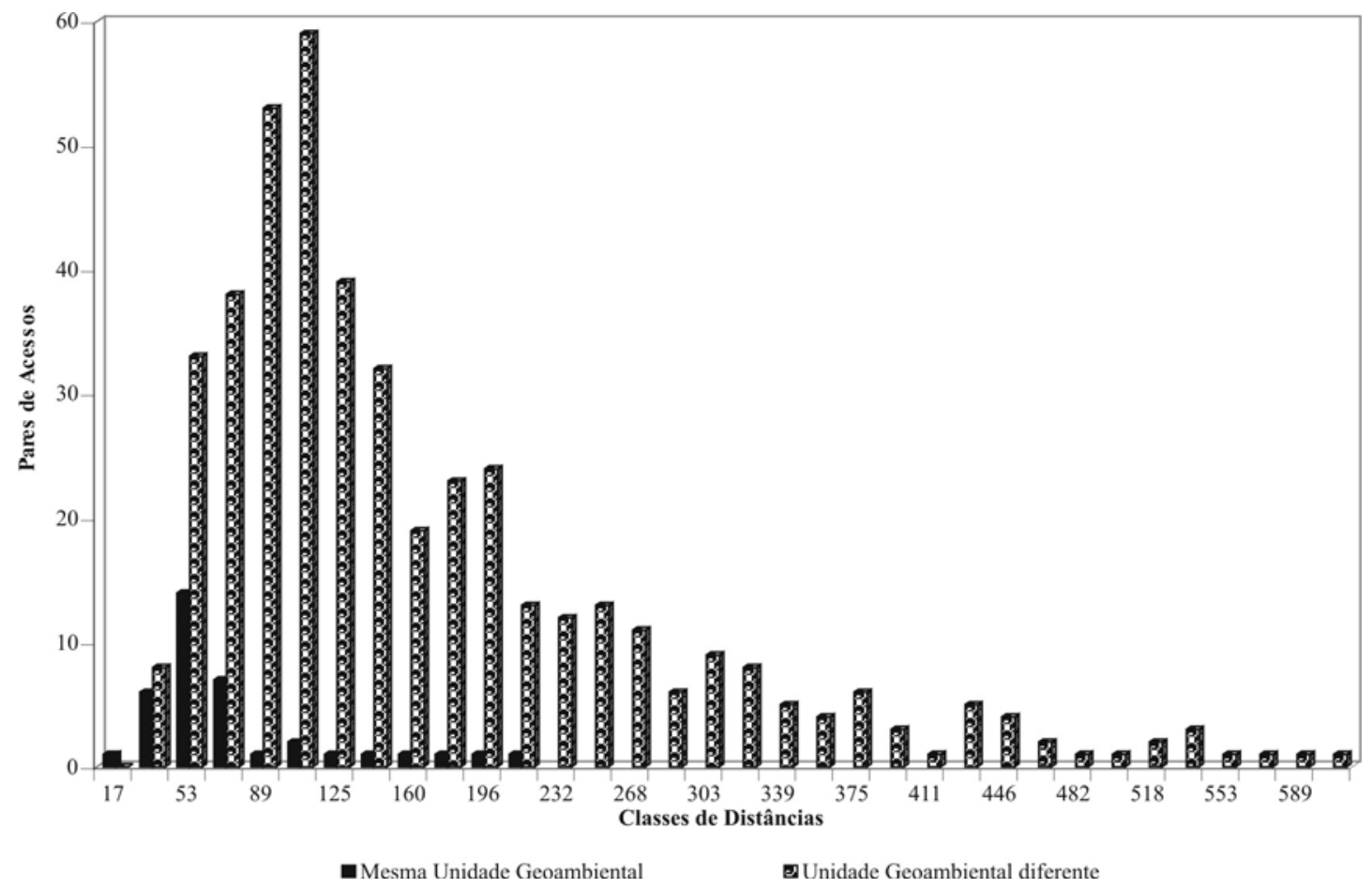

FIGURA 1- Distribuição de freqüência das estimativas de distância genética, obtida entre pares de 32 acessos de $P$. cincinnata. 
TABELA 1- Tratamentos, códigos das “UGs", relevo, coordenadas geográficas e municípios onde foram coletados os acessos de Passiflora cincinnata. Petrolina-PE, 2005.

\begin{tabular}{|c|c|c|c|c|c|c|}
\hline Trat/acesso' & Relevo & Longitude W & Latitude S & Altitude $(\mathrm{m})$ & Município/Origem & UF \\
\hline $1-\mathbf{A 0 4 2 3}$ & Chapadas altas & $39: 39: 36.00 \mathrm{~W}$ & $7: 23: 24.00 \mathrm{~S}$ & 930 & Crato & $\mathrm{CE}$ \\
\hline 2-A0424 & Chapadas altas & $39: 39: 36.00 \mathrm{~W}$ & $7: 23: 24.00 \mathrm{~S}$ & 935 & Crato & $\mathrm{CE}$ \\
\hline 3-A0425 & Chapadas altas & $39: 38: 24.00 \mathrm{~W}$ & 7:08:24.00 S & 942 & Nova Olinda & $\mathrm{CE}$ \\
\hline 4-A0429 & Chapadas altas & $39: 49: 48.00 \mathrm{~W}$ & $7: 06: 36.00 \mathrm{~S}$ & 649 & Assaré & $\mathrm{CE}$ \\
\hline 5-A0526 & Chapadas altas & $40: 20: 24.00 \mathrm{~W}$ & 7:04:48.00 S & 600 & Campos Sales & $\mathrm{CE}$ \\
\hline 6-A0527 & Chapadas altas & $40: 15: 00.00 \mathrm{~W}$ & $7: 09: 36.00 \mathrm{~S}$ & 618 & Exu & PE \\
\hline 7-B0451 & Chapadas intermediária baixa & $41: 12: 36.00 \mathrm{~W}$ & 7:00:36.00 S & 394 & Santo Antonio & PI \\
\hline 8-B0453 & Chapadas intermediária baixa & $41: 03: 36.00 \mathrm{~W}$ & $6: 52: 48.00 \mathrm{~S}$ & 561 & Monsenhor Hipólito & PI \\
\hline 9-B0549 & Chapadas intermediária baixa & 41:12:00.00 W & $7: 25: 12.00 \mathrm{~S}$ & 384 & Jaicós & PI \\
\hline $10-\mathrm{CO} 701$ & Chapada Diamantina & $41: 30: 36.00 \mathrm{~W}$ & $14: 49: 48.00 \mathrm{~S}$ & 720 & Tremedal & BA \\
\hline $11-\mathrm{CO} 702$ & Chapada Diamantina & 41:33:00.00 W & $14: 83: 35: 24 . \mathrm{S}$ & 725 & Tremedal & BA \\
\hline 12-C0703 & Chapada Diamantina & $42: 02: 24.00 \mathrm{~W}$ & $14: 58: 48.00 \mathrm{~S}$ & 689 & Condeuba & BA \\
\hline 13-C0704 & Chapada Diamantina & 42:02:24.00 W & $14: 58: 48.00 \mathrm{~S}$ & 718 & Condeuba & BA \\
\hline 14-CO705 & Chapada Diamantina & $42: 31: 48.00 \mathrm{~W}$ & $14: 52: 48.00 \mathrm{~S}$ & 768 & Jacaraci & BA \\
\hline $15-\mathrm{CO} 706$ & Chapada Diamantina & $42: 07: 12.00 \mathrm{~W}$ & $14: 33: 36.00 \mathrm{~S}$ & 656 & Guajeru & BA \\
\hline 16-C0707 & Chapada Diamantina & $42: 08: 24.00 \mathrm{~W}$ & $14: 33: 36.00 \mathrm{~S}$ & 728 & Jaguarari & BA \\
\hline 17-D0541 & Planalto da Borborema & $36: 09: 36.00 \mathrm{~W}$ & 7:10:48.00 S & 572 & Boa Vista & PB \\
\hline 18-D0542 & Planalto da Borborema & $36: 09: 36.00 \mathrm{~W}$ & $7: 10: 48.00 \mathrm{~S}$ & 574 & Boa Vista & PB \\
\hline 19-EO514 & Superficie retrabalhada & 40:09:00.00 W & 10:15:00.00 S & 633 & Jaguarari & BA \\
\hline 20-E0515 & Superficie retrabalhada & 40:06:36.00 W & $10: 13: 12.00 \mathrm{~S}$ & 551 & Jaguarari & BA \\
\hline 21-F1339 & Depressão Sertaneja & $37: 37: 48.00 \mathrm{~W}$ & $7: 29: 24.00 \mathrm{~S}$ & 738 & Agua Branca & PB \\
\hline $22-\mathbf{F 2 2} 16$ & Depressão Sertaneja & $39: 40: 12.00 \mathrm{~W}$ & $9: 43: 48.00 \mathrm{~S}$ & 494 & Petrolina & $\mathrm{PE}$ \\
\hline 23-F22 19 & Depressão Sertaneja & $40: 12: 00.00 \mathrm{~W}$ & $8: 03: 36.00 \mathrm{~S}$ & 459 & Ouricuri & PE \\
\hline 24-F2220 & Depressão Sertaneja & $40: 12: 00.00 \mathrm{~W}$ & $8: 34: 12.00 \mathrm{~S}$ & 459 & Ouricuri & PE \\
\hline $25-\mathbf{F} 2331$ & Depressão Sertaneja & $39: 40: 12.00 \mathrm{~W}$ & $9: 43: 48.00 \mathrm{~S}$ & 494 & Curaçá & $\mathrm{BA}$ \\
\hline 26-F2333 & Depressão Sertaneja & $39: 37: 48.00 \mathrm{~W}$ & 9:48:00.00 S & 529 & Uauá & BA \\
\hline 27-F2334 & Depressão Sertaneja & $39: 37: 48.00 \mathrm{~W}$ & 9:48:00.00 S & 528. & Uauá & BA \\
\hline $28-\mathbf{F 2 6 2 8}$ & Depressão Sertaneja & $40: 46: 12.00 \mathrm{~W}$ & $7: 07: 48.00 \mathrm{~S}$ & 640 & Potengi & $\mathrm{CE}$ \\
\hline 29-J0810 & Superficie Cársticas & $40: 24: 36.00 \mathrm{~W}$ & $9: 48: 36.00 \mathrm{~S}$ & 466 & Juazeiro & BA \\
\hline 30-J0812 & Superficie Cársticas & $40: 20: 24.00 \mathrm{~W}$ & $9: 49: 12.00 \mathrm{~S}$ & 489 & Juazeiro & BA \\
\hline $31-\mathbf{T 0 3 2} 1$ & Maciços e serras baixas & $39: 43: 48.00 \mathrm{~W}$ & $7: 33: 36.00 \mathrm{~S}$ & 540 & Exu & PE \\
\hline 32-T0336 & Maciços e serras baixas & $38: 50: 24.00 \mathrm{~W}$ & $8: 01: 12.00 \mathrm{~S}$ & 596 & S. J. do Belmonte & PE \\
\hline
\end{tabular}

${ }^{1}$ A04, A05, B04, B05, C07, D05, E05, F13, F16, F22, F23, F26, J08 e T03 correspondem às respectivas Unidades Geoambientais de caracterização do zoneamento agroecológico do Nordeste onde os acessos foram coletados.

TABELA 2 - Resumo da análise de variância de 23 caracteres avaliados em 32 acessos de Passiflora cincinnata Mast. no delineamento de blocos ao acaso. Petrolina-PE, 2005.

\begin{tabular}{|c|c|c|c|c|c|c|c|c|}
\hline \multirow{2}{*}{\multicolumn{2}{|c|}{ Caracteres }} & \multicolumn{3}{|c|}{ QUADRADOS MÉDIOS } & \multirow{2}{*}{ Mínimo } & \multirow{2}{*}{ Máximo } & \multirow{2}{*}{ Média } & \multirow{2}{*}{ C.V (\%) } \\
\hline & & Blocos & Acessos & Resíduo & & & & \\
\hline \multirow{2}{*}{ Planta } & $\overline{\mathrm{DH}}$ & 0,0082 & $0,0444^{* *}$ & 0,0047 & 0,45 & 1,01 & 0,7543 & 9,11 \\
\hline & $\mathrm{CIH}$ & 0,7487 & $2,3787 * *$ & 0,6192 & 5,30 & 10,0 & 7,2440 & 10,86 \\
\hline \multirow{3}{*}{ Folha } & $\mathrm{AF}$ & 970,7813 & $42272,9859 * *$ & 3115,8400 & 221,40 & 732,00 & 455,4007 & 12,25 \\
\hline & CMP & 0,2277 & $1,2643 * *$ & 0,2793 & 2,49 & 5,67 & 4,0807 & 12,95 \\
\hline & NGF & 0,1765 & $0,8939 * *$ & 0,1279 & 2,12 & 5,24 & 3,1492 & 11,36 \\
\hline \multirow{6}{*}{ Flor } & DAF & 1,1866 & $7,2699 * *$ & 1,7988 & 9,08 & 16,45 & 12,0768 & 11,10 \\
\hline & DFL & 0,0890 & $0,5827 * *$ & 0,1903 & 7,16 & 9,88 & 8,3864 & 5,20 \\
\hline & VP & 0,0422 & $4,9191 * *$ & 0,2482 & 4,09 & 9,81 & 8,5051 & 5,85 \\
\hline & CFE & 0,2292 & $0,3170^{* *}$ & 0,1121 & 3,85 & 5,70 & 4,6980 & 7,12 \\
\hline & $\mathrm{CB}$ & 0,0240 & $0,3480^{* *}$ & 0,0460 & 1,58 & 3,45 & 2,7448 & 7,82 \\
\hline & NGB & 0,0306 & $0,6623 * *$ & 0,0434 & 1,87 & 3,67 & 2,6782 & 7,87 \\
\hline \multirow{4}{*}{ Fruto } & MF & 217,3258 & $858,6002 * *$ & 82,5197 & 34,42 & 123,75 & 79,6752 & 11,40 \\
\hline & $\mathrm{CF}$ & 0,2320 & $0,3675 * *$ & 0,1519 & 4,25 & 6,66 & 5,4125 & 7,20 \\
\hline & DF & 0,2110 & $0,4092 * *$ & 0,0991 & 4,5 & 6,60 & 5,4879 & 5,73 \\
\hline & ECF & 0,0009 & $0,0105 * *$ & 0,0017 & 0,27 & 0,56 & 0,3887 & 10,61 \\
\hline \multirow{4}{*}{ Semente } & NSF & 10,4306 & $16,9273^{* *}$ & 3,0276 & 8,54 & 21,02 & 15,6758 & 11,09 \\
\hline & MS & 0,0161 & $0,3718^{* *}$ & 0,0720 & 4,09 & 5,83 & 4,9453 & 5,42 \\
\hline & $\mathrm{CS}$ & 0,0750 & $0,3807 * *$ & 0,0627 & 5,31 & 6,96 & 6,0172 & 4,16 \\
\hline & LS & 0,0209 & $0,1391 * *$ & 0,0239 & 3,09 & 4,27 & 3,5657 & 4,34 \\
\hline \multirow{2}{*}{$\begin{array}{l}\text { Químicos } \\
\text { dos frutos }\end{array}$} & SS & 0,2267 & $4,8570^{* *}$ & 1,0463 & 7,30 & 14,00 & 10,8127 & 9,46 \\
\hline & AT & 0,0477 & $1,3014 * *$ & 0,3420 & 2,37 & 6,38 & 4,7384 & 12,34 \\
\hline \multirow{2}{*}{ Produção } & NFT & 2,1356 & $75,879 * *$ & 2,66193 & 8,31 & 35,16 & 14,5268 & 11,23 \\
\hline & MTF & 14,4353 & $296,738 * *$ & 3,95849 & 4,92 & 46,8 & 15,8812 & 12,52 \\
\hline G.L & & 3 & 31 & 93 & & & & \\
\hline
\end{tabular}

G.L. $=$ Graus de liberdade. ${ }^{* *}$ Significativo a $1 \%$, pelo teste $\mathrm{F}$.
$\mathrm{DH}=$ diâmetro das hastes $(\mathrm{cm}) ; \mathrm{CIH}=$ comprimento dos internódios das hastes $(\mathrm{cm}) ; \mathrm{AF}=$ área foliar $\left(\mathrm{cm}^{2}\right) ; \mathrm{CMP}=$ comprimento médio do pecíolo $(\mathrm{cm}) ;$ $\mathrm{NGF}=$ número de glândulas foliares; $\mathrm{DAF}=$ número médio de dias do transplante para abertura da primeira flor; $\mathrm{DFL}=\mathrm{diâmetro}$ das flores $(\mathrm{cm}) ; \mathrm{VP}=$ $\mathrm{NGF}=$ número de glândulas foliares; DAF $=$ número médio de dias do transplante para abertura da primeira flor; DFL $=$ diâmetro das flores $(\mathrm{cm}) ; \mathrm{VP}=$
viabilidade de pólen $(\%) ; \mathrm{CFE}=$ comprimento dos filamentos da série externa $(\mathrm{cm}) ; \mathrm{CB}=$ comprimento das brácteas $(\mathrm{cm}) ; \mathrm{NGB}=$ número de glândulas viabilidade de pólen (\%); $\mathrm{CFE}=$ comprimento dos filamentos da série externa $(\mathrm{cm}) ; \mathrm{CB}=$ comprimento das brácteas $(\mathrm{cm}) ; \mathrm{NGB}=$ numero de glándula
nas brácteas; $\mathrm{MF}=$ massa média dos frutos $(\mathrm{g}) ; \mathrm{CF}=$ comprimento médio do fruto $(\mathrm{cm}) ; \mathrm{DF}=$ diâmetro médio do fruto $(\mathrm{cm}) ; \mathrm{ECF}=\mathrm{espessura}$ média da casca do fruto $(\mathrm{cm}) ; \mathrm{NSF}=$ número de sementes por fruto; $\mathrm{MS}=$ massa de 100 sementes $(\mathrm{g}) ; \mathrm{CS}=$ comprimento médio da semente $(\mathrm{mm}) \mathrm{LS}=1$ argura média da semente $(\mathrm{mm}) ; \mathrm{SS}=$ sólidos solúveis $\left({ }^{\circ} B r i x\right) ; \mathrm{AT}=$ acidez titulável $(\mathrm{g} / 100 \mathrm{~g}$ de suco); NFT = número total de frutos por planta; MTF = massa total de frutos por planta $(\mathrm{kg})$. 
TABELA - 3 Medidas de dissimilaridade da distância generalizada de Mahalanobis $\left(\mathrm{D}^{2}\right)$ entre pares de acessos de Passiflora cincinnata Mast. Petrolina-PE, 2005.

\begin{tabular}{lllllllllllllllllllllllllll}
\hline Acessos & 1
\end{tabular}

TABELA 4 - Grupos de acessos de Passiflora cincinnata Mast. estabelecidos pelo método de Tocher, com base na dissimilaridade expressa pela distância generalizada de Mahalanobis. Petrolina-PE, 2005.

\begin{tabular}{|c|c|c|}
\hline Grupos & Acessos & Distância média \\
\hline I & $\begin{array}{l}\text { 25-F2331; 26-F2333; 20-E0515; 23-F2219; 28-F2628; 5-A0526; 19-E0514; } \\
\text { 31-T0321; 29-J0810; 17-D0541; 1-A0423; 22-F2216; 7-B0451; 8-B0453; } \\
\text { 24-F2220. }\end{array}$ & 70,70 \\
\hline II & 10-C0701; 15-C0706; 16-C0707;14-C0705; 13-C0704; 11-C0702; 12-C0703. & 45,05 \\
\hline III & 2-A0424; 6-A0527; 4-A0429; 27-F2334; 21-F1339; 3-A0425 & 69,92 \\
\hline IV & 18-D0542; 32-T0336; & 64,31 \\
\hline $\mathrm{V}$ & 30-J0812 & - \\
\hline VI & 9-B0549 & . \\
\hline $\begin{array}{c}\text { Limite } \\
\text { intergrupo }(\theta)\end{array}$ & 89,82 & - \\
\hline
\end{tabular}

TABELA 5-Importância relativa dos descritores analisados para a divergência, em ordem decrescente de importância. Petrolina-PE, 2005.

\begin{tabular}{|c|c|}
\hline Descritor & Valor $(\%)$ \\
\hline Produção total de frutos (MTF) & 42,29 \\
\hline Viabilidade de pólen (VP) & 8,62 \\
\hline Área foliar (AF) & 7,17 \\
\hline Número de glândulas nas brácteas (NGB) & 5,88 \\
\hline Diâmetro das hastes (DH) & 4,99 \\
\hline Peso dos frutos (MF) & 4,03 \\
\hline Peso médio de 100 sementes $(\mathrm{PS})$ & 3,56 \\
\hline Número de glândulas foliares (NGF) & 2,82 \\
\hline Comprimento das brácteas (CB) & 2,64 \\
\hline Comprimento médio dos filamentos externos da flor ( $\mathrm{CFE}$ & 2,61 \\
\hline Sólidos solúveis(SS) & 2,50 \\
\hline Espessura da casca do fruto (ECF) & 2,48 \\
\hline Acidez titulável (AT) & 2,11 \\
\hline Número médio de sementes por fruto (NSF) & 1,65 \\
\hline Número médio de frutos por planta (NFT) & 1,56 \\
\hline Comprimento médio das sementes (CS) & 1,27 \\
\hline Comprimento médio do pecílo (CMP) & 1,03 \\
\hline Comprimento médio do internódio (ClH & 0,96 \\
\hline Dias para abertura da primeira flor (DAF) & 0,57 \\
\hline Diâmetro das flores (DFL) & 0,48 \\
\hline Largura média das sementes (LS) & 0,47 \\
\hline Diâmetro médio dos frutos (DF) & 0,43 \\
\hline Comprimento médio dos frutos (CF) & 0,15 \\
\hline
\end{tabular}

TABELA 6 - Coeficientes de correlação entre os descritores de maior importância (na horizontal) e os de menor importância (na vertical), para os 23 descritores morfológicos analisados. Petrolina-PE, 2005.

\begin{tabular}{cccccccccc}
\hline DESCRITOR & DH & AF & NGF & CB & NGB & VP & MF & MS & MTF \\
\hline CIH & $-0,0846$ & 0,1181 & 0,1003 & $-0,4074$ & 0,2123 & $-0,0472$ & 0,5294 & 0,2583 & $-0,3184$ \\
CMP & 0,5660 & $\mathbf{0 , 8 3 1 4}$ & 0,3882 & 0,3897 & $-0,6058$ & $-0,0824$ & 0,1364 & 0,1274 & $-0,6162$ \\
CFE & $-0,3696$ & $-0,1509$ &,- 04385 & $-0,0021$ & 0,1464 & $-0,2122$ & 0,2082 & $-0,1513$ & $-0,0058$ \\
DFL & $-0,1659$ & $-0,3718$ & 0,0939 & 0,0106 & 0,1207 & $-0,2860$ & $-0,4964$ & $-0,1714$ & 0,5325 \\
DAF & $-0,0258$ & 0,1018 & $-0,2872$ & $-0,3380$ & 0,0786 & $-0,0050$ & 0,5187 & $-0,0957$ & $-0,2232$ \\
CF & $-0,3947$ & $-0,1509$ & $-0,1082$ & 0,3221 & $-0,4110$ & 0,1794 & 0,3067 & $-0,3000$ & 0,1611 \\
DF & $-0,4547$ & $-0,2335$ & $-0,4325$ & $-0,2457$ & 0,3564 & $-0,0206$ & 0,5878 & 0,2563 & 0,1794 \\
ECF & 0,5342 & 0,5178 & 0,4092 & 0,4504 & $-0,6904$ & $-0,1719$ & $-0,0180$ & $-0,0889$ & $-0,4416$ \\
NSF & 0,4069 & 0,0879 & 0,2144 & $-0,1412$ & 0,2144 & 0,2506 & 0,0641 & $-0,0208$ & $-0,0201$ \\
CS & 0,6290 & 0,2735 & 0,5657 & $-0,0205$ & $-0,2058$ & 0,1734 & 0,2932 & $-0,3030$ & $-0,3618$ \\
LS & 0,4052 & 0,3601 & 0,1225 & $-0,2749$ & 0,0802 & 0,1383 & 0,5061 & $\mathbf{0 , 8 2 0 4}$ & $-0,4811$ \\
SS & 0,1152 & 0,3622 & 0,0603 & 0,5747 & $-0,3753$ & 0,5003 & $-0,2258$ & $-0,2921$ & $-0,0438$ \\
AT & 0,2446 & 0,2254 & 0,2352 & 0,2257 & $-0,3756$ & $-0,0066$ & 0,3154 & 0,3063 & $-0,3423$ \\
NFT & $-0,3074$ & $-0,6961$ & $-0,2399$ & $-0,1319$ & 0,4908 & $-0,4033$ & $-0,4552$ & $-0,0208$ & $\mathbf{0 , 9 3 0 6}$ \\
\hline
\end{tabular}
$\mathrm{DH}=$ diâmetro das hastes $(\mathrm{cm}) ; \mathrm{CIH}=$ comprimento dos internódios das hastes $(\mathrm{cm}) ; \mathrm{AF}=$ área foliar $\left(\mathrm{cm}^{2}\right) ; \mathrm{CMP}=$ comprimento médio do pecíolo $(\mathrm{cm}) ;$
$\mathrm{NGF}=$ número de glândulas foliares; $\mathrm{DAF}=$ número médio de dias do transplante para abertura da primeira flor; $\mathrm{DFL}=\mathrm{diâmetro}$ das flores $(\mathrm{cm}) ; \mathrm{VP}=$ $\mathrm{NGF}=$ número de glândulas foliares; $\mathrm{DAF}=$ número médio de dias do transplante para abertura da primeira flor; $\mathrm{DFL}=$ diâmetro das flores $(\mathrm{cm}) ; \mathrm{VP}=$
viabilidade de pólen $(\%) ; \mathrm{CFE}=$ comprimento dos filamentos da série externa $(\mathrm{cm}) ; \mathrm{CB}=$ comprimento de brácteas $(\mathrm{cm}) ; \mathrm{NGB}=$ número de glândulas nas brácteas; $\mathrm{MF}=$ massa média dos frutos $(\mathrm{g}) ; \mathrm{CF}=$ comprimento médio do fruto $(\mathrm{cm}) ; \mathrm{DF}=$ diâmetro médio do fruto $(\mathrm{cm}) ; \mathrm{ECF}=$ espessura média da casca do fruto $(\mathrm{cm}) ; \mathrm{NSF}=$ número de sementes por fruto; MS = massa de 100 sementes $(\mathrm{g}) ; \mathrm{CS}=$ comprimento médio da semente $(\mathrm{mm}) \mathrm{LS}=1$ largura da semente $(\mathrm{mm}) ; \mathrm{SS}=$ sólidos solúveis $\left({ }^{\circ} \mathrm{Brix}\right) ; \mathrm{AT}=$ acidez titulável $(\mathrm{g} / 100 \mathrm{~g}$ de suco); NFT $=$ número de frutos totais por planta; MTF $=$ massa total dos frutos por planta $(\mathrm{kg})$. 


\section{CONCLUSÕES} avaliados

1-Existe variabilidade entre os acessos de $P$. cincinnata

2-As características de maior importância para a divergência genética são: massa total dos frutos, viabilidade de pólen, área foliar, número de glândulas por bráctea, diâmetro das hastes, massa do fruto e da semente, e número de glândulas foliares.

3-O agrupamento dos acessos não se correlaciona com as Unidades Geoambientais originais de coleta.

4O acesso 18-D0542, indicado como o mais divergente, foi também o mais produtivo e, assim, deve ser recomendado para cultivos experimentais em áreas de produtores, bem como para compor futuros programas de intercruzamentos onde se vise à elevação de produtividade.

\section{REFERÊNCIAS}

AGRIANUAL 2005: anuário da agricultura brasileira. São Paulo: FNP, 2006. p. 359-365.

ALLARD, R.W. Princípios do melhoramento genético de plantas. Rio de Janeiro: USAID, 1971.331p

ASSOCIATION OF OFFICIAL AGRICULTURAL CHEMISTS. Official methods of analysis of the Association of the Agricultural Chemists. 12 $2^{\text {th }}$ ed. Washington, DC, 1992.

BENIN, G.; CARVALHO, F. I. F de; OLIVEIRA, A. C. de; MARCHIORO, V. S; LORENCETTI, C.; KUEK, A. J.; SILVA, J. A. G.; CRUZ, P. J.; HARTWING, I.; SCHMIDT, D. A. M. Comparações entre medidas de dissimilaridade e estatística multivariadas como critérios no direcionamento de hibridações em aveia. Ciência Rural, Santa Maria, v. 33, p. 657-662, 2003.

BERNACCI, L. C. Passifloraceae. In: WANDERLEY, M.. L.; SHEPHERD, G. J.; GIULIETT, A. M.; MELHEM, T. S. (Coord.). Flora Fanerogâmica do Estado de São Paulo. São Paulo: FAPESP, 2003. v. 3, p. 247-248.

COSTA, A M.; TUPINAMBÁ, D. D. O maracujá e suas propriedades medicinais - estado de arte. In: FALEIRO, F. G.; JUNQUEIRA, N. T. V.; BRAGA, M. F. (Ed.). Maracujá: germoplasma e melhoramento genético. Planaltina: Embrapa Cerrados, 2005. cap. 20, p. 475-506

CROCHEMORE, M. L.; MOLINARI, H. B.; STENZEL, N. M. C. Caracterização agromorfológica do maracujazeiro (Passiflora spp.). Revista Brasileira de Fruticultura, Jaboticabal, v. 25, n. 1, p.5-10, 2003.
CRUZ, C. D. Aplicação de algumas técnicas multivariadas no melhoramento genético de plantas. 1990. 188 f. Tese (Doutorado em Agronomia - Melhoramento Genético de Plantas) - Escola Superior de Agricultura Luiz de Queiroz, Piracicaba, 1990.

CRUZ, C. D.; REGAZZI, J. A.; CARNEIRO, P. C. S. Divergência genética. In: CRUZ, C. D.; REGAZZI, J. A.; CARNEIRO, P. C. S. (Ed.). Modelos biométricos aplicados ao melhoramento genético. Viçosa: UFV, 2004. v.1, p.377-413.

CRUZ, C. D.; CARNEIRO P. C. S. Modelos biométricos aplicados ao melhoramento genético. Viçosa: UFV, 2003. v. 2. 585p.

CRUZ, C.D. Programa GENES: versão Windows - aplicativo computacional em genética e estatística. Viçosa: UFV, 2001. 648p.

DIAS, L. A. dos S; KAGEYAMA, P. Y.; CASTRO, G. C. T. Divergência genética multivariada na preservação de germoplasma de cacau (Theobroma cacao L.) Agrotrópica, Ilhéus, v.9, p. 29-40, 1997.

FERREIRA, F. R. Recursos Genéticos de Passiflora. In: FALEIRO, F. G.; JUNQUEIRA, N. T. V.; BRAGA, M. F. (Ed.). Maracujá: germoplasma e melhoramento genético. Planaltina: Embrapa Cerrados, 2005. cap. 2, p. 41-51.

INGLEZ DE SOUSA, J. S; MELETTI, L. M. M. Maracujá: espécies, variedades e cultivo. Piracicaba: FEALQ, 1997. 179 p. (Biblioteca de Ciências Agrárias Luiz de Queiroz, 3).

INSTITUTO ADOLFO LUTZ. Normas analíticas, métodos químicos e físicos para análise de alimentos. 3. ed. São Paulo, 1985. v.1,371p

JUNQUEIRA, N. T. V.; BRAGA, M. F.; FALEIRO, F. G.; PEIXOTO, J. R.; BERNACCI, L. C. Potencial de espécies silvestres de maracujazeiro como fonte de resistência a doenças. In: FALEIRO, F. G.; JUNQUEIRA, N. T. V.; BRAGA, M. F. (Ed.). Maracujá: germoplasma e melhoramento genético. Planaltina: Embrapa Cerrados, 2005. cap. 4, p. 81-107.

MACDOUGAL, J. M.; FEUILLET, C. Systematics. In: ULMER, T. MACDOUGAL, J. M. Passiflora:Passionflower of the Wold. Portland: Timber Press, 2004. cap. 2, p, 27-31.

MELETTI, L. M. M.; SOARES-SCOT, M. D.; BERNACCI, L. C.; PASSOS, I. R. da S Melhoramento genético do maracujá: passado e futuro. In: FALEIRO, F. G.; JUNQUEIRA, N. T. V.; BRAGA, M. F. (Ed.). Maracujá: germoplasma e melhoramento genético. Planaltina: Embrapa Cerrados, 2005. cap. 3, p. 55-78.

MELETTI, L. M. M.; SOARES-SCOTT, M. D.; BERNACCI, L. C.; MARTINS, F. P. Caracterização de germoplasma de maracujazeiro (Passiflora $\mathrm{sp}$ ). Revista Brasileira de Fruticultura, Cruz das Almas, v. 14, n. 2, p. 157-162, 1992. 
MUSCHNER, V.C.; LORENZ, A. ;CERVI, A. C.; BONATTO, S.L. ;SOUZA-CHIES,T. T.; SALZANO,F.M.; FREITAS, L. B. A firt molecular phylogenetic analysis of Passiflora (Passifloraceae). American Jounal of Botany, New York, v.90. n. p. 1229-1238, 2003.

OLIVEIRA, F.J de; ANUNCIAÇÃO FILHO, C. J. da; BASTOS, G. Q; REIS, O. V dos. Divergência genética entre cultivares de caupi. Pesquisa Agropecuária Brasileira, Brasília, v. 38, n.5, p. 605611, maio. 2003.

PETER, K. V.;RAI, B. Genetic divergence in tomato. Indian Jounal of Genetics and plant Breeding, New Delhi, v.36, n. 3, p. 379-383, 1976.

QUEIROZ, M. A. de; NASCIMENTO, C. E. de S.; SILVA, C. M. M. de ; LIMA, J. L. dos S. Fruteiras nativas do semi-árido do Nordeste brasileiro: algumas reflexões sobre os recursos genéticos. In: SIMPÓSIO NACIONAL DE RECURSOS GENÉTICOS DE FRUTEIRAS NATIVAS, 1992, Cruz das Almas, BA. Anais... Cruz das Almas: EMBRAPA-CNPMF, 1993. p. 87-92.
RAO, C. R. Advanced statistical methods in biometric research. New York: J. Wiley, 1952.390 p.

RADFORD, A. E.; DICKISON, W. C.; MASSEY, J. R.; BELL, C. R. Vascular plant systematics. New York: Harper and Row, 1974. $891 \mathrm{p}$.

SINGH, D. The relative importance of characters affecting genetic divergence. Indian Journal of Genetic and Plant Breeding, New Delhi, v.41, p.237-245, 1981.

SILVA, F. B. R. e; SANTOS, J. C. P. dos; SOUZA NETO, N. C. de; SILVA, A. B. da; RICHE, G. R.; TONNEAU, J. P.; CORREIA, R. C.; BRITO, L. T. de L.; SILVA, F. H. B. B. da; SOUZA, L. de G. M. C.; SILVA, C. P. da; LEITE, A. P.; OLIVEIRA NETO, M. B. de. Zoneamento agroecológico do Nordeste do Brasil: diagnóstico e prognóstico. Recife: Embrapa Solos, Petrolina: Embrapa SemiÁrido, 2000. 1 CD-ROM. (Documentos, 14) 